\title{
Factors Affecting Motivation of Primary Health Care Workers in West Arsi Zone, Oromia Region, South East of Ethiopia
}

Tura Koshe Haso $^{1^{*}}$, Sheka Shemsi Seid ${ }^{1}$, Shamsedin Amme lbro ${ }^{1}$ and Fikrtemariam Abebe ${ }^{2}$

${ }^{1}$ School of Nursing and Midwifery, Institute of Health, Jimma University, Ethiopia

${ }^{2}$ School of Allied Health Sciences, Department of Nursing, Addis Ababa University, Ethiopia

"Corresponding author: Tura Koshe Haso, School of Nursing and Midwifery, Institute of Health, Jimma university, Ethiopia, Tel: 251-916-060-634; E-mail: turaakeenya@gmail.com

Received date: January 18, 2018; Accepted date: January 24, 2018; Published date: January 27, 2018

Copyright: @ 2018 Haso TK, et al. This is an open-access article distributed under the terms of the Creative Commons Attribution License, which permits unrestricted use, distribution, and reproduction in any medium, provided the original author and source are credited.

\begin{abstract}
Background: There is the fact that low health worker motivation may affect the success of health care system. Therefore this study is aimed at identifying factors affecting motivation of primary health workers working at public health centers of West Arsi zone of Ethiopia.
\end{abstract}

Methods: This facility based was a cross-sectional study, pretested questionnaire were self-administered to 307 health workers from various clinical specialties. The responses were collected and analyzed; results were presented in frequency and tables.

Results: This study revealed that considerable proportions, $41.7 \%$ of the participants were demotivated towards providing routine health care of clients. Job satisfaction and professional advancements were factors positively affecting motivation of the respondents. Respondents' attained professional advancements were 3.5 times more likely motivated than those not advanced providers. Likewise, the odd of being motivated for those satisfied at their job was 5 times higher than those unsatisfied at their jobs.

Conclusions: Significant numbers of the primary health care providers participated in this study were found to be demotivated towards jobs. Job satisfaction and professional advancements were factors influencing job motivation among the primary health care providers. Therefore, administrative measures aiming at raising the primary health care providers' motivation should be placed.

Keywords: Motivation; Health care workers; Primary health care

\section{Introduction}

Human resources determine the use of other available resources but human resource management systems are facing serious problems in developing countries. Evidence indicates that the inheritance of continuous under-investment in human resources may possibly lead to the underachievement of health care services $[1,2]$. The motivation of primary health care provider is identified as the determinant of the health sector performance. Therefore ensuring this is very significant to effectively deliver health service in several developing countries [3].

Motivation can be defined as "individual's degree of willingness to exert and maintain an effort towards attaining organizational goals" [4].

Several studies revealed that motivated health personnel are more likely to apply their knowledge and skill to the real establishment of health care and it also indicated that the efficient use of the skills of a well-motivated health workforce contribute to a lot provide and effective health care services [5-8]. Health worker motivation can possibly influence the establishment of health care services provisions. However, in developing and middle income countries low staff motivation and shortage of human resources for health are factors that are disabling health systems and health care provisions $[1,2,4,5]$. It is stated that the Primary health care provider's motivation and satisfaction have been affected by several factors [5]. These factors include good management, supervisors and managers' support and good working relationship with colleagues, financial aspects, career development, continuing education, health facility infrastructure $[5,9]$. Theories related to motivation also identifies intrinsic factors like recognition, works itself, responsibility, advancement, promotion which and extrinsic factors like organization policy, relationship with (peers, subordinates and supervisor), working conditions, salaries, status and security which could significantly related to motivation [10]. These factors become a key constraints to achieving the millennium development goals (MDGs) and crippling already fragile health care systems in low and middle-income countries like Ethiopia [11].

In Ethiopia different recent studies revealed that manpower in the health service is small and (41.4\%)of them are demotivated to stay at assigned health facilities and In Oromia region only $63.63 \%$ of health professions working in public health facilities highly motivated. Management at different levels of the health care delivery system appears to be led by health professionals who have no motivation, even no training $[1,2,12]$. To have motivated and well skill work force employee, fulfilling the basic need and supportive needs like comprehensive training, appreciating, appropriate payment and safe guarding the life of workers were the key agents to achieve proposed goal regarding reduction of morbidity and mortality in different region of the country [13]. The different studies conducted in our countries also indicated that there is the fact that low health worker motivation 
may affect the success of health sector reforms and programs and it is found that less health care provider's motivation and scarcity of human resources for health $(\mathrm{HRH})$ are factors that are affecting health systems and health care. Despite this, the growth of health workforce has been given less consideration at international and country levels until $[1,2,12]$. Generally, low motivation can compromise the performance of individual health workers, facilities and the health system as a whole. Moreover, the objectives of the health system are not being attained in most countries because of serious human resource policy crises, particularly of poor motivation [13]. The researchers have found limited documented research findings in Ethiopia that identify factors affecting motivation of health care providers. Such information is critical to guide further improvement of the performance of individual health workers. This information will also be useful to other researchers to conduct large-scale studies on the same issue. Understanding the factors affecting motivation will also help policy and decision maker to improve the motivation level of primary health care workers. Hence, the study aimed at identifying factors influencing motivation of primary health care workers in West Arsi zone of south east Ethiopia.

\section{Methods and Materials}

\section{Study design and setting}

Facility based cross-sectional study design was conducted from March 1/03/2017 to April 1/04/2017 in public health centers of seven woredas in West Arsi Zone, Oromia regional state, which is found at South East, Ethiopia (251 km far from capital Addis Ababa). As per West Arsi zone health bureau statistics, there are 84 operating government owned health facilities ( 3 hospitals and 81 health centers) offering preventive and curative services to Populations among other services. The study population was made up of all health care providers who were working in public health center in the district of West Arsi Zone. There are a total of 1115 health center workers. Health centers are mainly staffed by registered nurses, midwives, public health officer's pharmacists, environmental health Workers, and Medical laboratory technicians while medical doctors are not employed in health centers because this category is mostly employed at District Hospital or beyond. A total of 307 of primary health care workers were selected by from the public health facilities located in the districts of west Arsi zone of Ethiopia.

\section{Sample size determination}

Sample size was determined using the formula for single population proportion based on the following assumptions.

$$
n=\frac{(Z \alpha / 2)^{2} p(1-p)}{d^{2}}
$$

Where: $\mathrm{n}=$ is the size of the sample

$Z \alpha / 2=$ is the standard normal value corresponding to the desired level of confidence (95\%)

$\mathrm{d}=$ error of precision $(5 \%)$

$\mathrm{P}=\mathrm{is}$ the estimated proportion of motivation which is $58.6 \%$ (19)

$$
n=\frac{(1.96)^{2}(0.586)(1-0.586)=373}{(0.05)^{2}}
$$

Because the total population is less than 10,000 which is 1115 , sample size was determination by using the correction formula as follow:-

$$
N f=\frac{373}{1+373 / 1115}=279.4 \approx 279
$$

By adding $10 \%$ non-response rate total sample size became $(279+28)=307$

\section{Sampling procedure and sampling technique}

The target population comprised 1115 PHC workers at health centers in the west Arsi zone. A total of 307 primary health care workers were selected from the health centers located in seven districts of west Arsi zone by using simple random sampling technique. Next the determined sample is proportionally allocated to each districts (i.e. Shashamane (69), Kofele (54), Shalla (52) and Dodola (61), Wondo (23), Kore (21), Bishan Guracha (27)). Then the sample proportionally allocated to each districts was proportionally allocated to the number of each health center in each districts. Finally, Simple Random Sampling technique was used to select study units from list of human resource profile of health centers.

\section{Data collection tools and data collection procedure}

Data were collected by using pretested and structured selfadministered English version questionnaires. The questionnaire was adapted from guide enhancing organizational performance and selfassessment tools box [12]. The questionnaire comprised of two parts which included: socio-demographic characteristics (age, sex, ethnicity, religion, educational status and marital status, and factors affecting motivations including (satisfaction, advancement, and promotion). Measures were taken to ensure the quality of collected data. The questionnaire was pretested among $5 \%$ of the sample size in similar set up (Arsi Negele district health center) before the actual data collection and necessary changes were then made. The purpose of data collection and the importance of the study as well as the significance of true information were also enlightened to participants in order to maximize the response rate and generate reliable data. The data collectors were also trained on interview to enhance data accuracy and validity. There was close supervision of the data collectors by the researchers.

\section{Data analysis procedure}

The collected data was critically checked for its completeness then coded and entered by using Epidata 3.1, and exported to SPSS version 20. Reliability tests were employed on SPSS to check the instrument internal consistency. Descriptive statistics was used to describe each individual variable using mean, standard deviation and other methods. To test whether there is relationship between dependent variables and independent first checked by binary regression and then independent variables which had a P-value of less than 0.2 in bivariate analysis were entered to multivariate analysis to get adjusted odd ratio. The strength of association was determined using crude odds ratio in the bivariate analysis and adjusted odds ratio in multivariate analysis. The data was analyzed using descriptive statistics and presented with diagrams, tables and figures. Significant of statistical association was assured or tested using 95\% confidence interval $(\mathrm{CI})$ and p-value $(<0.05)$. Results were summarized in frequencies and percentages. 
Citation: Haso TK, Seid SS, Ibro SA, Abebe F (2018) Factors Affecting Motivation of Primary Health Care Workers in West Arsi Zone, Oromia Region, South East of Ethiopia. Adv Practice Nurs 3: 146. doi:10.4172/2573-0347.1000146

Page 3 of 6

\section{Results}

\section{Socio-demographic characteristics}

A total of 307 health care providers were took part in the study. Half, $154(50.2 \%)$ of the respondents were males, while $76(57.3 \%)$ of them were in the age range of 25-29 years with mean (SD) age of 27.51 (4.168). Above than half of the participants have five or less years of work experiences, 169 (55.04\%), and 79 (25.7\%) attained diploma in academic qualification, and $161(52.7 \%)$ paid monthly payments of above than three thousands of Ethiopian birr (Table 1).

\begin{tabular}{|c|c|c|c|}
\hline Variable & Category & Frequency & Percentage (\%) \\
\hline \multirow{6}{*}{ Age } & $20-24$ & 67 & 21.8 \\
\hline & $25-29$ & 176 & 57.3 \\
\hline & $30-34$ & 48 & 15.75 \\
\hline & $35-39$ & 10 & 3.25 \\
\hline & $\geq 40$ & 6 & 1.9 \\
\hline & Total & 307 & 100 \\
\hline \multirow{3}{*}{ Sex } & Male & 154 & 50.2 \\
\hline & Female & 153 & 49.8 \\
\hline & Total & 307 & 100 \\
\hline \multirow{5}{*}{ Service year } & $<5$ & 169 & 55.04 \\
\hline & 05-Oct & 124 & 40.39 \\
\hline & Nov-15 & 9 & 2.93 \\
\hline & $\geq 16$ & 5 & 1.64 \\
\hline & Total & 307 & 100 \\
\hline \multirow{7}{*}{ Profession } & Nurses & 97 & 31.6 \\
\hline & Midwifes & 64 & 20.8 \\
\hline & Pharmacist & 39 & 12.7 \\
\hline & Health officer & 45 & 14.7 \\
\hline & Laboratory technician & 58 & 18.9 \\
\hline & Environmental health & 4 & 1.3 \\
\hline & Total & 307 & 100 \\
\hline \multirow{3}{*}{ Educational qualification } & Diploma & 194 & 63.2 \\
\hline & Bachelor & 113 & 36.8 \\
\hline & Total & 307 & 100 \\
\hline \multirow{4}{*}{ Monthly Income } & $1000-2000$ & 26 & 8.5 \\
\hline & $2001-3000$ & 119 & 38.8 \\
\hline & $\geq 3001$ & 162 & 52.7 \\
\hline & Total & 307 & 100 \\
\hline
\end{tabular}

Table 1: Socio-demographic characteristic of study respondents at primary health care in West Arsi Zone, Oromia Region, South East of Ethiopia, 2017(N=307).

\section{Motivation status}

More than half of the present study participants, 179(58.3\%) were motivated towards providing routine care for their clients, while significant proportions, $128(41.7 \%)$ reported to be demotivated to do their routine activities (Table 2). 
Citation: Haso TK, Seid SS, Ibro SA, Abebe F (2018) Factors Affecting Motivation of Primary Health Care Workers in West Arsi Zone, Oromia Region, South East of Ethiopia. Adv Practice Nurs 3: 146. doi:10.4172/2573-0347.1000146

Page 4 of 6

Out of all respondents, 161(52.4\%) were responded satisfied with their job. Regarding to the working environments $161(52.4 \%)$ and $146(47.6 \%)$ study participants reported that they were working at favorable and unfavorable working environment respectively.

$80(26 \%)$ and $227(74 \%)$ of study participants were reported that they are working under the supervision of democratic and non-democratic managers respectively. Concerning the salary, out of 179 motivated health workers $134(43.6 \%)$ of the respondents reported that their salary was adequate while the remaining $173(56.4 \%)$ were reported as it is not adequate (Table 2).

\begin{tabular}{|c|c|c|c|c|c|c|c|}
\hline \multirow{3}{*}{ Variables } & \multirow{3}{*}{ Category } & \multicolumn{6}{|c|}{ Motivation status } \\
\hline & & \multicolumn{2}{|l|}{ Motivated } & \multicolumn{2}{|c|}{ Demotivated } & \multicolumn{2}{|l|}{ Total } \\
\hline & & Frequency & Percentage (\%) & Frequency & Percentage (\%) & Frequency & Percentage (\%) \\
\hline \multirow{3}{*}{ Satisfaction } & Satisfied & 129 & 42 & 32 & 10.4 & 161 & 52.4 \\
\hline & Dissatisfied & 50 & 16.3 & 96 & 31.3 & 146 & 47.6 \\
\hline & Total & 179 & 58.3 & 128 & 41.7 & 307 & 100 \\
\hline \multirow{3}{*}{ Working Environment } & Favorable & 101 & 32.9 & 60 & 19.5 & 161 & 52.4 \\
\hline & Unfavorable & 78 & 25.4 & 68 & 22.2 & 146 & 47.6 \\
\hline & Total & 179 & 58.3 & 128 & 41.7 & 307 & 100 \\
\hline \multirow{3}{*}{ Management style } & Democratic & 60 & 19.5 & 20 & 6.5 & 80 & 26 \\
\hline & Non democratic & 119 & 38.8 & 108 & 35.2 & 227 & 74 \\
\hline & Total & 179 & 58.3 & 128 & 41.7 & 307 & 100 \\
\hline \multirow{3}{*}{ Salary } & Adequate & 98 & 31.9 & 36 & 11.7 & 134 & 43.6 \\
\hline & Not Adequate & 81 & 26.4 & 92 & 30 & 173 & 56.4 \\
\hline & Total & 179 & 58.3 & 128 & 41.7 & 307 & 100 \\
\hline \multirow{3}{*}{ Advancement } & Advanced & 116 & 37.8 & 31 & 10.1 & 147 & 47.9 \\
\hline & Not advanced & 63 & 20.5 & 97 & 31.6 & 160 & 52.1 \\
\hline & Total & 179 & 58.3 & 128 & 41.7 & 307 & 100 \\
\hline
\end{tabular}

Table 2: Motivational status of primary health care workers in West Arsi Zone, Oromia Region, South East of Ethiopia, 2017(N=307).

\section{Factors associated with motivation}

In a logistic regression model, it was found that Satisfaction of study participants were positively affected with participants' motivation to their routine care $(\mathrm{P}$-value $=0.000)$.

This means satisfied health care providers were 5.287 times more likely to be motivated to their routine care than dissatisfied health care providers [AOR (95\% CI) 5.287(3.061,9.131) P-value 0.000)]. The advancement of health care providers was also found to be positively associated with motivation of health care providers.

Those health care providers who advanced were 3.5 times more likely to be motivated than who did not advanced health care providers [AOR 3.472(1.995,6.045) and p-value of 0.000] (Table 3).

\begin{tabular}{|c|c|c|c|c|c|}
\hline \multicolumn{2}{|l|}{ Variables } & \multicolumn{4}{|c|}{ Level of motivation } \\
\hline & & \multirow{2}{*}{$\begin{array}{l}\text { Motivated No (\%) } \\
129(42.0)\end{array}$} & \multirow{2}{*}{$\begin{array}{l}\text { Demotivated N (\%) } \\
32\end{array}$} & \multirow{3}{*}{$\begin{array}{l}\text { COR }(95 \% \mathrm{Cl}) \\
7.740(4.618,12.972)\end{array}$} & \multirow{3}{*}{$\begin{array}{l}\text { AOR }(95 \% \mathrm{Cl}) \\
5.287(3.061,9.131)^{\star *}\end{array}$} \\
\hline \multirow{2}{*}{ Satisfaction } & Satisfied & & & & \\
\hline & Dissatisfied & $50(16.3)$ & 96 & & \\
\hline \multirow{2}{*}{ Management } & Democratic & $60(19.5)$ & 20 & \multirow{2}{*}{$2.723(1.541,4.810)$} & \multirow{2}{*}{$1.030(0.504,2.106)$} \\
\hline & Nondemocratic & $119(38.8)$ & 108 & & \\
\hline Salary & Adequate & 98 & 36 & $3.092(1.904,5.024)$ & $1.390(0.759,2.546)$ \\
\hline
\end{tabular}


Page 5 of 6

\begin{tabular}{|l|l|l|l|l|l|}
\hline & Not adequate & 81 & 92 & & \\
\hline \multirow{2}{*}{ Advancement } & Advanced & 116 & 31 & \multirow{2}{*}{$5.761(3.468,9.571)$} & $3.472(1.995,6.045)^{* *}$ \\
\cline { 2 - 5 } & Not advanced & 63 & 97 & & \\
\hline
\end{tabular}

Table 3: Factors associated with motivation of study respondents of primary health care at West Arsi zone, Oromia Region South East of Ethiopia, 2017(N=307).

\section{Discussion}

This study showed that the overall motivation of the West Arsi zone primary health care provider were $58.3 \%$. This finding is different from a study conducted on motivation and factors affecting it among health professionals in the public hospitals, Central Ethiopia which revealed that the overall motivation level of health professionals was $63.63 \%$ [2]. This difference may be due to the difference in socio-political system between the study areas. But this finding is similar with another study conducted at public hospitals of West Amhara in Ethiopia which showed that $58.6 \%$ of study participants were motivated. This similarity might be due almost similar income and allowance, geographical similarity, similarity in methodological, nearly similar sample size and sampling method used [1].

This study indicated that there is no statistically significant relationship between socio-demographic variables and their motivation and this is similar with the study conducted central Ethiopia but inconsistent with another study conducted in Addis Abeba public hospital which shown that nurses' motivation be influenced by age (18). This difference might be due to the difference in study setting, study participants. The study conducted in Addis Abeba was carried at public hospitals and included only nursing health professionals.

This study stated that he main motivating factors for health workers were Satisfaction level of health profession. In this study $52 \%$ found to be satisfied with their jobs. This finding is greater than the study conducted in Jimma University which has shown that $41.4 \%$ of study participants were found to be satisfied at their job [14]. This discrepancy could be due the difference with the study setting and qualification of the participants. This study is conducted in primary health care like health centers, health posts and very few district hospitals which are almost staffed with many diplomas and few bachelor health professionals while in study conducted Jimma university referral hospital which is almost staffed with highly qualified health professionals.

In another hand in this study working environment, management style, salary and qualification of the professionals were not found to be significantly associated with their motivation. But is finding inconsistent with several another studies which has been done elsewhere on similar issues $[1,2,4,5,7,8]$

An advancement of health professionals was associated with their motivation. This means an advanced health care provider were 3.47 times more likely to be motivated care providers than not advanced health care providers. However other similar study conducted in Federal hospitals of Ethiopia revealed that those who had opportunity to develop were 2.3 times more likely to be motivated when compared to those who had not opportunity to develop. This indicates that the recent study is higher than previously study conducted. The reason of discrepancy might be due to the difference in study area, degree of their highest qualification (for present study majority of them were diploma nurse) and place of residence of health workers (Rural (present study) vs rural (previous study) [15].

In conclusion motivation of health professionals was affected by different factors: these are satisfaction and an advancement of health care professionals. A significant percentage of participants thought that the current advancement or promotion positively influenced their motivation.

In general this study revealed that the proportion demotivated PHC worker in the study setting was high (41.7\%). In another way satisfaction and advancement of care providers were positively affect the motivation level of health care providers. The health system have to enhance the promotion and morale of care providers and have to increase the motivation of health staffs by providing necessary supplies and increasing the satisfaction and promotion in order to increase the quality of health care at different level of prevention and curative aspects. Finally further large scale study with a representative sample size is recommended to be conducted in same study area in the future.

The findings of this study should be interpreted in the light of its limitations this study was conducted in the nine districts of west Arsi zone of Ethiopia. The target population comprised PHC care workers based at health centers in west Arsi zone of Oromia region, Ethiopia. Therefore, the study findings can be generalized only to the study setting. The study results cannot be generalized to the rest of the whole Oromia region or Ethiopia. As in all cross-sectional studies, we can infer association but not causation from our results. The result of this study depended on self-report of PHC workers and as a result there might be influence of social desirability; nevertheless, the study was confidential and data collectors were instructed to guarantee that their responses could not be related to them.

\section{Ethical Considerations}

The study secured ethical clearance from the Institutional Review Board (IRB) of Addis Ababa University, Department of Nursing and Midwifery. Authorized letter was obtained from West Arsi zone Health District. Study participants were informed about the purpose of the study, their right to refuse or withdraw from the study. Confidentiality was ensured by excluding their names or address in the questionnaire and final report. There were no psychological or social risks or discomforts involved in participating in this study.

\section{Competing interests}

The authors declare that they have no competing interests.

\section{Funding}

Funding for this study was made possible through grants offered by Addis Ababa University post graduate office. 
Citation: Haso TK, Seid SS, Ibro SA, Abebe F (2018) Factors Affecting Motivation of Primary Health Care Workers in West Arsi Zone, Oromia Region, South East of Ethiopia. Adv Practice Nurs 3: 146. doi:10.4172/2573-0347.1000146

Page 6 of 6

\section{Authors' Contributions}

Haso TK conceptualized the paper, searched literature, trained field researchers for data collection and wrote the results and discussion sections. He also wrote the draft manuscript. Seid SS contributed to the design of the study and provided advice as regards methods, data interpretation and Ibro SA analyzed the data. He also critically reviewed and edited the manuscript. All authors read and approved the final manuscript

\section{Acknowledgments}

We are grateful to Addis Ababa University, College of Health Sciences, School of Allied Health, for its financial and technical support. We are also very indebted to extend our gratitude to West Arsi zone of Oromia regional state health bureau and the District administration office for their kind assistance during the entire process of the study. The authors are also thankful to the respondents who offered their time to participate in this study. Special thanks go to the research assistants who participated in data collection.

\section{References}

1. Weldegebriel Z, Ejigu Y, Weldegebreal F, Woldie M (2016) Motivation of health workers and associated factors in public hospitals of West Amhara, Northwest Ethiopia. Patient Prefer Adherence 10: 159-169.

2. Dagne T, Beyene W, Berhanu N (2015) Motivation and factors affecting it among health professionals in the public Hospitals, Central Ethiopia. Ethopian J Heal Sci 25: 231-242.

3. Peters DH, Chakraborty S, Mahapatra P, Steinhardt L (2010) Job satisfaction and motivation of health workers in public and private sectors: Cross-sectional analysis from two Indian states. Hum Resour Health 8: 1-11.

4. Mbindyo P, Blaauw D, Gilson L, English M (2009) Developing a tool to measure health worker motivation in district hospitals in Kenya. Human Resources for Health 7: 40.
5. Daneshkohan A, Zarei E, Mansouri T, Maajani K, Ghasemi MS, et al. (2014) Factors affecting job motivation among health workers: A study from Iran. Glob J Health Sci 7: 153-160.

6. Prytherch H, Kagon M, Aninanya GA, Williams JE, Kakoko DC, et al. (2013) Motivation and incentives of rural maternal and neonatal health care providers: A comparison of qualitative findings from Burkina Faso, Ghana and Tanzania. BMC Health Serv Res 13: 149.

7. George MS, Pant S, Devasenapathy N, Ghosh-Jerath S, Zodpey SP (2017) Motivating and demotivating factors for community health workers: A qualitative study in urban slums of Delhi, India. WHO South-East Asia J Public Heal 6: 82-89.

8. Ojakaa D, Olango S, Jarvis J (2014) Factors affecting motivation and retention of primary health care workers in three disparate regions in Kenya. Hum Resour Health 12: 33.

9. Mbilinyi D, Daniel ML, Lie GT (2011) Health worker motivation in the context of HIV care and treatment challenges in Mbeya Region, Tanzania: A qualitative study. BMC Health Serv Res 11: 266.

10. Ebuehi O, Campbell P (2011) Attraction and retention of qualified health workers to rural areas in Nigeria: A case study of four LGAs in Ogun State, Nigeria. Rural Remote Health 11: 1515.

11. Willis-Shattuck M, Bidwell P, Thomas S, Wyness L, Blaauw D, et al. (2008) Motivation and retention of health workers in developing countries: A systematic review. BMC Health Serv Res 8: 1-8.

12. Kibebe $G$ (2015) Assessment of factors affecting motivation of health care providers working in public heath centers in addis ababa: AAU.

13. Initiative JL (2004) Human resources for health: Overcoming the crisis. Global Equity Initiative.

14. Yami A, Hamza L, Hassen A, Jira C, Sudhakar M (2011) Job satisfaction and its determinants among health workers in jimma university specialized hospital, Southwest Ethiopia. Ethiop J Health Sci 21: 19-27.

15. Tadese T, Mohamed A, Mengistie A (2016) Assessment of factors influencing job satisfaction among health care providers, federal police referral hospital, Addis Ababa, Ethiopia. Ethiop J Health Dev 29: 119-126. 